\title{
Evidence-based guidelines for use of probiotics in preterm neonates
}

\author{
Girish C Deshpande ${ }^{1,2}$, Shripada C Rao ${ }^{3,4,5}$, Anthony D Keil ${ }^{3,6}$ and Sanjay K Patole ${ }^{3,5^{*}}$
}

\begin{abstract}
Background: Current evidence indicates that probiotic supplementation significantly reduces allcause mortality and definite necrotising enterocolitis without significant adverse effects in preterm neonates. As the debate about the pros and cons of routine probiotic supplementation continues, many institutions are satisfied with the current evidence and wish to use probiotics routinely. Because of the lack of detail on many practical aspects of probiotic supplementation, clinician-friendly guidelines are urgently needed to optimise use of probiotics in preterm neonates.
\end{abstract}

Aim: To develop evidence-based guidelines for probiotic supplementation in preterm neonates.

Methods: To develop core guidelines on use of probiotics, including strain selection, dose and duration of supplementation, we primarily used the data from our recent updated systematic review of randomised controlled trials. For equally important issues including strain identification, monitoring for adverse effects, product format, storage and transport, and regulatory hurdles, a comprehensive literature search, covering the period 1966-2010 without restriction on the study design, was conducted, using the databases PubMed and EMBASE, and the proceedings of scientific conferences; these data were used in our updated systematic review.

Results: In this review, we present guidelines, including level of evidence, for the practical aspects (for example, strain selection, dose, duration, clinical and laboratory surveillance) of probiotic supplementation, and for dealing with non-clinical but important issues (for example, regulatory requirements, product format). Evidence was

\footnotetext{
* Correspondence: sanjay.patole@health.wa.gov.au

${ }^{3}$ Department of Neonatal Paediatrics, KEM Hospital for Women, Perth, Australia
}

Full list of author information is available at the end of the article inadequate in some areas, and these should be a target for further research.

Conclusion: We hope that these evidence-based guidelines will help to optimise the use of probiotics in preterm neonates. Continued research is essential to provide answers to the current gaps in knowledge about probiotics.

\section{Background}

Despite the advances in neonatal intensive care over past 20 years [1], the incidence of necrotising enterocolitis (NEC) in preterm neonates has not changed significantly. The mortality (approximately 20 to $25 \%$ ) and morbidity related to definite (greater than stage II) NEC, including prolonged hospitalisation [2], survival with short-bowel syndrome $[3,4]$ and long-term neurodevelopmental impairment (NDI) continues to be high, especially in preterm or extremely low birth weight (ELBW) (birth weight $<1000 \mathrm{~g}$, gestation $<28$ weeks) neonates needing surgery for this illness [5]. Mortality reaches nearly $100 \%$ in children with extensive and full-thickness necrosis of the gut $[6,7]$.

Antenatal use of glucocorticoids, with postnatally, preferential feeding with fresh human milk, aggressive prevention and treatment of sepsis, and a cautious uniform approach to enteral feeds are the strategies available to prevent NEC [8]. Previous systematic reviews of randomised controlled trials (RCTs) showed that probiotic supplementation significantly reduces the risk of definite NEC, all-cause mortality and the time to reach full enteral feeds $(\sim 120$ to $150 \mathrm{ml} / \mathrm{kg} /$ day of milk) in preterm neonates [9-11]. Based on these results, reports have indicated that routine probiotic supplementation is justified, except for ELBW neonates, given the lack of specific data on this high-risk cohort $[12,13]$. Our most recent updated systematic review and meta-analysis confirmed previous results, while improving their precision and reducing the likelihood of these being due to chance alone (Table 1) [14]. Moreover, trial sequential
C Biomed Central

(C) 2011 Deshpande et al; licensee BioMed Central Ltd. This is an Open Access article distributed under the terms of the Creative Commons Attribution License (http://creativecommons.org/licenses/by/2.0), which permits unrestricted use, distribution, and reproduction in any medium, provided the original work is properly cited. 
Table 1 Updated systematic review results (Pediatrics 2010)

\begin{tabular}{llll}
\hline Outcome & $\mathbf{R R}^{\mathbf{a}}$ (95\% Cl) & $\boldsymbol{P}$ value & $\mathbf{N N T}^{\mathbf{b}}\left(\mathbf{9 5} \% \mathbf{C l}^{\mathbf{c}}\right)$ \\
\hline NEC & $0.35(0.23$ to 0.55$)$ & 0.00001 & $25(17$ to 34$)$ \\
Mortality & $0.42(0.29$ to 0.62$)$ & 0.00001 & $20(14$ to 34$)$ \\
Sepsis & $0.98(0.81$ to 1.18$)$ & 0.80 & $\mathrm{~N}^{\mathbf{d}}$ \\
\hline
\end{tabular}

${ }^{\mathrm{a}}$ Relative risk.

${ }^{\mathrm{b}}$ Confidence interval.

${ }^{c}$ Numbers needed to treat.

${ }^{\mathrm{d}}$ Not available.

analysis (TSA) indicated that the results gave conclusive evidence of at least $30 \%$ reduction in the incidence of NEC. These conclusive results, along with those from observational studies on routine use of probiotics, their use in ELBW neonates $[15,16]$, and their safety and possible benefits in terms of long-term NDI, justify a change in practice if safe and suitable probiotic products are available [17]. Some have supported our views [18], but others cite difficulties such as problems in pooling data in the presence of clinical heterogeneity, reproducibility of the results in different studies, role of breast milk, pitfalls of TSA, lack of availability of safe and effective products, development of antibiotic resistance, cross-contamination and long-term adverse effects (AEs) as reasons for opposing routine use of probiotics in preterm neonates [19-23]. We have previously addressed these concerns [24], and pointed out that probiotic research has completed a full circle, from basic science [25] and cohort studies [26], to conclusive meta-analysis [14], routine use [15], and long-term follow up [16,17]. Many level III neonatal units in Japan, Italy, Finland and Columbia have been using probiotics routinely for over a decade, and have not reported any significant AEs $[15,27,28]$. Based on the quality and totality of the evidence in the context of the related health burden and the lack of equally effective therapies, we believe that probiotics should be offered routinely to preterm neonates. Additionally, from the perspective of a preterm neonate or their family, there would need to be a good reason to ignore the evidence base for using probiotics to prevent NEC. Offering probiotics routinely, but still within a framework of research other than placebo-controlled trials, is the way forward to deal with the as yet unanswered questions $[14,24]$. As the debate about the pros and cons of routine probiotic supplementation continues, many institutions are satisfied with the current evidence and wish to use probiotics routinely. Because of the lack of detail on many practical aspects of probiotic supplementation, clinician-friendly guidelines are urgently needed to optimise use of probiotics in preterm neonates.

Because of the vast scope of the field, we aimed to conduct a comprehensive rather than a conventional systematic review in order to develop evidence-based guidelines for using probiotics in preterm neonates, and we indicate areas for further exploration of this new frontier.

\section{Methods}

To develop the core guidelines for strain selection, age at start, dose and duration of the supplementation, we primarily used the data from RCTs of probiotics in preterm neonates from our recent updated systematic review [14].

For equally important issues such as strain identification, AEs, product format, storage and transport, regulatory issues, ethics and parent information, the relevant literature was searched in PubMed (1966 to October 2010) and EMBASE for the period 1980 to October 2010, and we also used the search engine Google.

PubMed was searched using the following terms: "Probiotics"[MeSH] AND "Culture Techniques"[MeSH]; "Probiotics"[MeSH] AND "Classification"[MeSH]; "Probiotics"[MeSH] AND "Bacterial Translocation"[MeSH]; "Probiotics"[MeSH] AND "Sepsis"[MeSH]; "Probiotics"[$\mathrm{MeSH}] \mathrm{AND}$ "Informed Consent"[MeSH]; "Probiotics"[$\mathrm{MeSH}] \quad \mathrm{AND}$ "Legislation, Drug"[MeSH]; "Probiotics"[MeSH] AND ("Ethics"[MeSH] OR "Ethics Committees"[MeSH] OR "Ethics Committees, Clinical"[$\mathrm{MeSH}] \mathrm{OR}$ "Codes of Ethics"[MeSH] OR "Ethics Committees, Research"[MeSH] OR "Ethics, Clinical"[MeSH] OR "Ethics, Professional"[MeSH] OR "Ethics, Medical"[$\mathrm{MeSH}] \mathrm{OR}$ "Bioethics"[MeSH]); "Probiotics"[MeSH] AND Refrigeration"[MeSH] "Probiotics"[MeSH] AND "Quality Control"[MeSH]; "Probiotics"[MeSH] AND "Quality Assurance, Health Care"[MeSH].

EMBASE was searched using the following terms: probiotic.mp. or probiotic agent AND microbiological examination/or culture medium/or methodology/or culture methods.mp. or culture technique/or bacterium culture/; probiotic.mp. or probiotic agent AND antibiotic susceptibility.mp. or antibiotic sensitivity; probiotic. mp. or probiotic agent AND Sepsis; probiotic.mp. or probiotic agent AND bacterial translocation; probiotic. mp. or probiotic agent AND legislation.mp. or licence/ or law/; probiotic.mp. or probiotic agent AND informed consent; probiotics.mp. or probiotic agent AND temperature/or drug storage/or drug packaging/or cold chain.mp. or drug stability/or freezing/; probiotic.mp. or probiotic agent quality assurance.mp. or quality control/.

The search covered studies in the neonatal, paediatric and adult populations, and also in animal studies and in vitro studies. Cross-references from the relevant studies were also searched. Specific references that were used to develop the guidelines are quoted in the main manuscript of the review. All other essential or related references are included in the appendices (see Additional file 
1; see Additional file 2), which also include the results of the PubMed and EMBASE search strategies.

An attempt to search Google search engine using the aforementioned terms was abandoned, as it resulted in hits ranging from 838 to $1,690,000$. PRISMA guidelines for reporting the systematic review were followed where applicable [29].

When establishing guidelines, it is preferable to grade the level of evidence (LOE) depending on the type and the quality of study. However, we found that there are no validated and universally accepted methods for assessing the quality of studies) especially for studies other than RCTs), or for grading the LOE [30-37]. Our core guidelines are based on the systematic review of RCTs of probiotic supplementation in preterm very low birth weight (VLBW) neonates. The quality of these trials was assessed by the method recommended by the Cochrane Neonatal Review Group and by Jadad scores, which are commonly used but have not been validated $[38,39]$.

The development and reporting of crucial aspects of probiotics (for example, selection, manufacturing, transport, storage, quality control (QC), and regulation) has not necessarily followed the model of evidence-based medicine, making it difficult to apply the principles of LOE to every aspect of this intervention. It is also difficult to apply the conventional concept of study design and LOE for bench research to practical issues such as stability and taxonomy confirmation. We therefore adopted a simple method of grading the LOE, based on a pyramid of evidence hierarchy, with systematic reviews of RCTs being at the top (best evidence) and a case series being the bottom [33] (Figure 1). We believe that this simple system for grading the LOE along with the judgement of the readers will be adequate to permit appropriate interpretation of the various aspects of the guidelines.

\section{Results}

\section{Selection of strains}

Bifidobacteria and lactobacilli are the species of choice in probiotics, given the evolution of the gut flora in preterm neonates [40-42]. However, lactobacilli are a minor component of the intestinal microbiota. In terms of the rationale for species and strain selection, it is important to note that there are many different mechanisms producing the benefits of probiotics and there are also strain-specific effects. Bifidobacteria are the dominant strains in infancy, and the combination of lactobacilli and bifidobacteria is known to promote the growth of indigenous lactic-acid bacteria (bifidogenic effect) by formation of short-chain fatty acids as a product of the fermentation process $[41,43,44]$.

Strains isolated from humans are preferable because of their natural occurrence, long-term record of safety in infants, and adaptability to both mucosal and dairy ecosystems $[45,46]$. Researchers have generally selected strains belonging to bacterial species naturally present in the intestinal flora of the species to be targeted (in this case, humans), under the assumption that these bacteria have a better chance of out-competing resident bacteria and of establishing themselves at a numerically significant level in their new host [45]. However, because humans have shared such strains with other mammals for millions of years, other researchers believe that their origin is difficult to trace as they are present everywhere: in human beings, animals, soil, food and water. Thus, bovine strains may also be used if they have a good record of safety and efficacy. It is the specificity of the action rather than the source of the microorganism that is important. The clinical significance of the origin of strains may be evaluated in future trials [45,47-51]. The probiotic strains that have been used in various RCTs in preterm neonates are summarised in Table 2[52-62].

It is important to note that the probiotic effects are strain-specific, and cannot be extrapolated to other strains. The variability of the strains and protocols in the trials included in our meta-analysis indicates that the concept of strain-specific effects of probiotics may not be relevant to prevention of NEC by probiotics. Because of the various complex pathways involved in the pathogenesis of NEC, different strains may benefit by different pathways [63]. The benefits of different

\begin{tabular}{ll}
\hline Level of evidence & Study design \\
\hline I & Evidence obtained from a systematic review of all relevant randomised controlled trials \\
II & Evidence obtained from at least one properly-designed randomised controlled trial \\
III-I & Evidence obtained from well-designed pseudorandomised controlled trials (alternate allocation or some other method) \\
$\mathrm{III-2}$ & Evidence obtained from comparative studies (including systematic reviews of such studies) with concurrent controls and \\
$\mathrm{III-3}$ & allocation not randomised, cohort studies, case-control studies, or interrupted time series with a control group \\
$\mathrm{IV}$ & Evidence obtained from comparative studies with historical control, two or more single arm studies, or interrupted time \\
series without a parallel control group
\end{tabular}

Figure 1 Designations of levels of evidence. Figure from Merlin et al. BMC Medical Research Methodology 2009: 34, doi:10.1186/1471-2288-9-34. 
Table 2 Probiotic protocols from trials included in the updated meta-analysis

\begin{tabular}{|c|c|c|}
\hline Study & Probiotic agent/s & Dose and duration \\
\hline $\begin{array}{l}\text { Kitajima } \\
1997[52]\end{array}$ & Bifidobacterium breve & $0.5 \times 10^{9} \mathrm{cfu}^{\mathrm{a}}$ once daily from first feed for 28 days. \\
\hline $\begin{array}{l}\text { Dani } 2002 \\
{[53]} \\
\end{array}$ & Lactobacillus rhamnosus GG & $6 \times 10^{9} \mathrm{cfu}$ once daily from first feed until discharge \\
\hline $\begin{array}{l}\text { Costalos } \\
2003[54]\end{array}$ & Saccharomyces boulardii & $10^{9} / \mathrm{kg}$ twice daily from first feed for 30 days \\
\hline $\begin{array}{l}\text { Bin Nun } \\
2005[55]\end{array}$ & $\begin{array}{l}\text { Bifidobacterium infantis, Streptococcus } \\
\text { thermophilus, Bifidobacterium bifidus }\end{array}$ & $\begin{array}{l}0.35 \times 10^{9} \mathrm{cfu} B \text {. infantis, } 0.35 \times 10^{9} \mathrm{cfu} \text { S. thermophilus and } 0.35 \times 10^{9} \mathrm{cfu} \text { B. bifidus } \\
\text { once daily from first feed to } 36 \text { weeks corrected age }\end{array}$ \\
\hline $\begin{array}{l}\operatorname{Lin} 2005 \\
{[56]}\end{array}$ & Lactobacillus acidophilus, B. infantis & $\begin{array}{l}1004356 \text { L. acidophilus and } 1015697 \text { B. infantis organisms twice daily from day } 7 \text { until } \\
\text { discharge }\end{array}$ \\
\hline $\begin{array}{l}\text { Manzoni } \\
2006[57]\end{array}$ & Lactobacillus casei & $6 \times 10^{9} \mathrm{cfu}$ once daily from 3 days to 6 weeks of age, or discharge from NICU \\
\hline $\begin{array}{l}\text { Mohan } \\
2006[28]\end{array}$ & Bifidobacterium lactis & $\begin{array}{l}1.6 \times 10^{9} \text { cfu once daily from day } 1 \text { to day } 3 ; 4.8 \times 10^{9} \text { cfu once daily from day } 4 \text { to } \\
\text { day } 21\end{array}$ \\
\hline $\begin{array}{l}\text { Stratiki } \\
2007[59]\end{array}$ & B. lactis & Preterm formula: $1 \times 10^{7} \mathrm{cfu} / \mathrm{g}$ started within 48 hours to 30 days \\
\hline $\begin{array}{l}\operatorname{Lin} 2008 \\
{[60]}\end{array}$ & B. bifidus, L. acidophilus & $2 \times 10^{9}$ cfu daily for 6 weeks \\
\hline $\begin{array}{l}\text { Samanta } \\
2009[61]\end{array}$ & B. bifidus, B. lactis, B. infantis, L.s acidophilus & $2.5 \times 10^{9}$ cfu daily until discharge \\
\hline $\begin{array}{l}\text { Rouge } \\
2009[62]\end{array}$ & Bifidobacterium longum, Lactobacillus GG & $1 \times 10^{8}$ cfu daily until discharge \\
\hline
\end{tabular}

${ }^{\mathrm{a} C o l o n y-f o r m i n g ~ u n i t s . ~}$

${ }^{\mathrm{b}}$ Neonatal intensive-care unit.

probiotics in infective diarrhea indicate that although many probiotic effects are strain-specific, others may be similar for very different probiotic organisms [64]. The variation in the immunomodulatory effects between species is generally larger than that between the strains of the same species [65]. The rates of gut colonisation by a probiotic strain also differ according to the age of the host $[52,66,67]$.

Evidence indicates that the functionality of a multistrain or multispecies probiotic could be more effective and more consistent than that of a monostrain probiotic $[46,68,69]$. Researchers have also investigated the adequacy of combinations of strains [70]. Colonisation of an ecosystem providing a niche for more than 400 species in combination with individually determined host factors is anticipated to be more successful with multistrain rather than monostrain probiotic preparations $[46,50,71,72]$. The results of one review indicated that multistrain probiotics showed greater efficacy than single strains, including single strains that were components of the mixtures themselves. It was unclear whether this was due to synergistic interactions between strains or to the higher probiotic dose used in some studies [73]. Based on the complexity of normal gut flora and of NEC pathogenesis, and the multiple beneficial mechanisms of probiotic strains, multistrain probiotics may be more effective than single-strain probiotics $[63,74]$.
However, the report of a consensus meeting of experts states that a combination of probiotic strains in a product does not necessarily add to the benefits of each strain [75]. A high number of different strains is not, in itself, indicative of greater efficacy than a lower number of strains [75]. Clinical trials are needed to address the benefits of single-versus multistrain probiotic products in preterm neonates.

Our systematic review of RCTs indicates that the trials reporting a significant decline in NEC used multistrain products $[55,56,60]$, whereas those reporting a lesser decline used a single organism, such as Lactobacillus rhamnosus GG [52-54]. Failure of Lactobacillus GG to prevent NEC in the RCT reported by Dani et al. and in the report of 12 years' experience by Luoto et al. suggests that it may be prudent to avoid the use of this single strain alone, pending further evidence $[27,28,53]$. The potential of Bifidobacterium animalis (subspecies lactis) also needs to be explored [58,59,76].

Using more than two or three strains (each with an optimal mass) may result in higher risk of translocation because of the substantial increase in the total dose, especially in ELBW neonates; however, without an optimal mass of each component, a combination may not be effective in assuring survival and colonisation by each strain of the supplement. It is better to avoid untested combinations, because strain combinations can be antagonistic, compatible or synergistic [77]. 
It would be reasonable to use probiotic products that have previously been shown to be effective in RCTs, provided the evidence indicates that there has been no change or compromise in the manufacturing technique $[55,56]$.

\section{Dose}

An optimal mass or dose is essential for any probiotic strain to survive and colonise the gut. The concept of viability refers to the ability of the probiotic strain to survive and proliferate in 'adequate' numbers to benefit the host. It is hence expected that there will be an optimal dose below which benefits may not occur, as survival and proliferation to adequate numbers, after overcoming the barriers such as gastric acid, bile and competing flora, is not ensured $[78,79]$. Evidence indicates that to be functional, probiotics have to be viable and in sufficient dosage levels, typically $10^{6}$ to $10^{7} \mathrm{col}-$ ony-forming units $(\mathrm{cfu}) / \mathrm{g}$ of product $[46,80,81]$.

Conventional dose-response studies could be conducted in preterm neonates; however the selected doses will be arbitrary, and only guessed from what is known about the gut ecosystem in preterm neonates. There is no data on the toxic or lethal dose of probiotics for preterm neonates, and extrapolating from studies in other populations and animal experiments is likely to be incorrect [82]. An expert consensus report stated that '... there is no standardised number of probiotic bacteria that would ensure an effect [75]. The effective quantity, for a given effect and a given strain, is the quantity which has demonstrated an effect in the relevant human intervention trial'. In addition, live probiotics have the potential to replicate in the gut and lead to bacteremia. Judicious consideration is hence important in applying the principle of dose-response studies to this high-risk population with associated poor nutrition, impaired immune status and frequent exposure to infectious agents [83]. Conducting crossover and forced-titration (stepwise dose-escalation) dose-response studies will also be difficult, as the incidence of NEC is known to fluctuate over time. As for parallel design, the definition of a target dose is subjective.

Based on the median dose used in the RCTs in preterm neonates (Table 2), we suggest that a daily dose of $3 \times 10^{9} \mathrm{cfu} /$ day may be appropriate for neonates of less than 32 weeks gestation. Currently, there are no data available regarding a dose beyond which the risk of probiotic complications will be high in ELBW neonates. Until such data are available, we suggest that the starting dose should be $1.5 \times 10^{9} \mathrm{cfu} /$ day for ELBW neonates until they reach enteral feeds of 50 to $60 \mathrm{ml} / \mathrm{kg} /$ day. Halving the volume of the probiotic supplement should also benefit these neonates because they are often intolerant to large enteral volumes [84]. The reduced dose is still expected to be beneficial, based on the lower clinically effective doses used in the trials in our updated meta-analysis [55].

Investigators of one recent trial suggested that the daily probiotic dose in malnourished children should preferably be given as a single rather than divided dose, in view of the rapid decline of the strain mass in vivo [85]. The osmotic load, $\mathrm{pH}$ and volume of a single dose are crucial in ELBW neonates because of their inability to tolerate even very small volumes of milk feeds in the early days of life [86]. The nature of diluent (dextrose, sterile water, saline, milk) and volume after dilution are also important practical issues. The currently recommended range of osmolarity of neonatal milk formulae is 246 to $320 \mathrm{mOsm} / \mathrm{kg}$ [87]. The osmotic load of drugs and milk additives is a concern in high-risk neonates because of the risk of NEC [88-90]. Adequate dilution is thus necessary to avoid undue hyperosmolarity.

\section{When to start?}

Because of the importance of early establishment of commensal flora in preterm neonates [40,41,91], the probiotic supplementation should be started as early as possible before pathogens colonise or antibiotics destroy the prevailing commensals. The earliest reported age at start of supplementation was 4 hours of life, in the study by Satoh et al. [15]. Otherwise most of the investigators assessed (7/ 11) started the supplementation when the neonates were ready for enteral feeds (Table 2). Clinical stability (for example, no sepsis, patent ductus arteriosus, inotropes or ileus) is desirable to ensure that the gut function has recovered after the initial illness, with minimal risk of intolerance or translocation. The optimal protocol for probiotic administration in ELBW neonates with intrauterine growth restriction needs to be confirmed [92].

\section{When to stop?}

It is well known from animal and human (both adults and children) studies that shedding of probiotic organisms in the stool commonly stops about 2 to 3 weeks after the probiotic supplement is stopped $[48,69,78,93]$. Hence continued administration is necessary to promote sustained colonisation in preterm neonates until evidence is available for this high-risk population. Based on the published trials (Table 2) and the inverse relation of gestational age with NEC and all-cause mortality, it seems appropriate that supplementation could be stopped after reaching the corrected gestational age of 36 to 37 weeks, when the risk of these adverse outcomes is minimal.

\section{Supplementation in the presence of potentially compromised gut integrity}

The risk of probiotic translocation and sepsis is higher in critically ill and/or extremely preterm neonates with 
potentially compromised gut integrity [94-98], and may be higher in the presence of high doses of a single strain. The current evidence is inadequate to make clear recommendations in this area [14]. Investigators reported increased mortality in recipients of probiotic (compared with placebo) in an RCT involving adults with acute pancreatitis [99]. These findings may relate to non-occlusive mesenteric ischemia in critical illness, which is exacerbated by the added bacterial load itself or a pro-inflammatory response by gut epithelial cells [100]. Extrapolating these findings to critically ill and/or extremely preterm neonates may not be appropriate, but stopping the supplementation during an acute illness (for example, proven or suspected sepsis, NEC, perinatal asphyxia) may be in the best interest of the child, pending further evidence [101]. Studies are needed to identify the optimal use of probiotics in such neonates.

\section{Clinical monitoring during supplementation}

Intolerance (higher osmotic load causing abdominal distension, diarrhea or vomiting), probiotic sepsis and AEs (flatulence, loose stools) of additives such as prebiotic oligosaccharides need to be monitored [102]. However, the significant overlap of features of ileus of prematurity, sepsis and NEC is expected to make this issue very difficult. Frequent clinical examinations and a cautious approach are desirable until enough experience is obtained with a probiotic product and protocol in this high-risk cohort.

\section{Ongoing laboratory surveillance for safety}

On-site expert microbiological support is vital for independent taxonomy confirmation, exclusion of contaminants and confirmation of colony counts in the reconstituted product. Microbiology laboratories should ensure that their culture media are capable of recovering the constituent bacterial species, especially at low inoculums from sterile sites. Additionally, they should be familiar with the Gram stain and phenotypic appearances of the probiotics in different media, and be aware of the possible need for extended incubation times in anaerobic conditions. In the few published reports of bacteraemia with probiotics, there is scant detail about the blood culture manufacturer or system or the media used [103-106]. Clinical isolates should be compared with probiotic strains using molecular methods such as 16S rRNA sequencing and pulsed-field gel electrophoresis [107]. The possibility of cross-contamination, resulting in nosocomial acquisition of probiotic strains by other children in the neonatal unit, should not be forgotten. Kitajima et al. reported colonisation rates of $73 \%$ and $91 \%$ in their probiotic group versus $12 \%$ and $44 \%$ in the control group neonates at 2 and 6 weeks respectively [52]. Costeloe et al. reported cross-contamination rates of $35 \%$ in their pilot clinical trial. This possibility needs to be discussed with the parents of the children in neonatal units providing probiotic supplementation. It is important for researchers to note that cross-contamination in the control arm in an RCT is expected to underestimate the true effects of probiotics [108]. Antibiotic susceptibility testing of probiotics by standardised methods should be undertaken to provide local guidance for empiric antibiotic prescribing [103-107,109,110]. The frequency of in vivo transfer of antibiotic-resistance mechanisms is currently unknown. The role of routine fecal surveillance cultures to detect such transfer is also unknown, and is likely to be beyond the scope of routine laboratories. Other important issues are the stability of the probiotic on transport and shelf storage, ability of the laboratory to rapidly detect probiotic sepsis, and surveillance for the development of antibiotic resistance. Regular random stool cultures are beneficial but need extra resources. Compared with lactobacilli, culturing bifidobacteria is difficult as it requires special media and expertise [111]. The rarity of bifidobacterial sepsis in the literature could relate to failure to isolate these strains in blood culture by particular techniques. Newer nonculture methods are a better option. Extensive ongoing microbiological monitoring may not be necessary if the safety and quality (from manufacturing, transport and storage on-site to use in the neonatal unit) of the probiotic product is ensured $[82,112,113]$.

\section{Practical issues}

Variations in the manufacturing process can significantly alter the properties of probiotic strains [51,112,114]. Variations between batches in the quality of dietary supplements are also known to occur [115]. Assurance of good manufacturing practices is thus important [116]. The choice of the packaging material plays an important role in maintaining the viability of the probiotic strains at sufficiently high levels to ensure their therapeutic activity throughout shelf life. Probiotics, by current definition, are live microorganisms that survive in the anaerobic environment of the gut, and are sensitive to oxygen, moisture and heat. Their production and packaging should therefore involve limiting their exposure to oxygen by using barrier packages and eliminating oxygen by flushing with nitrogen. The support compounds should have minimal moisture. Refrigeration is important to protect the product from significant temperature fluctuations. The product format (dry powder, sachets, ready-to-use liquid, capsules, tablets) is an important issue, as we have recently reported poor viability of strains in probiotic tablets [117].

Based on the current understanding that viability (ability to survive, proliferate and benefit the host) is an important property of probiotic strains, the proportion 
of viable strains in a probiotic product will be an essential determinant of its clinical efficacy. This necessitates a high degree of stringency in the manufacturing process, as required by regulatory agencies. However, evidence indicates that dead or inactivated probiotic strains, or even their cellular components and culture broths, can still have beneficial effects [118-120]. If further clinical research provides evidence to this effect, the proportion of viable strains in a probiotic product may not be a crucial issue. However, it is important to note that even if viability of the strains does not turn out to be a crucial issue in the future, the level of stringency required in the manufacturing process cannot be compromised, because there are other important issues involved, such as taxonomy confirmation and contamination. Wastage after administration of a small dose, and stability and contamination of the leftover dose are also practical issues, and availability of a product in different strengths may solve this problem. Assurance of regular supply and ready availability of a standby product is important in view of the ongoing need for routine use and research, and prevention of inflation in pricing due to the monopoly of one product.

\section{Role of prebiotics in probiotic products}

The coexistence of probiotics and prebiotics, as found in human breast milk, is known to be synergistic [121,122]. Prebiotics have been shown to enhance the survival of endogenous probiotic organisms [123,124]. Further research, such as RCTs of probiotics versus synbiotics, is necessary to evaluate whether addition of prebiotics improves the survival and/or efficacy of probiotic strains in preterm neonates [125].

\section{Regulatory issues}

There has been a poor track record of QC of some commercially available products [126-128], thus improvisation and standardisation of the regulatory guidelines is urgently needed. The first option involves the central regulatory agencies (for example, in Australia, this is the Therapeutic Goods Administration (TGA)) taking the responsibility of approving the $\mathrm{QC}$ and quality assurance (QA) practices in the manufacturing plant, and facilitating the development of a central QC laboratory for providing national backup services for independent ongoing confirmation of quality. However, this option runs the risks of administrative delays, overburdening of the central laboratory, and complete dependency of all neonatal units on its services. The second option involves development of a central QC laboratory for each state to supervise or assist the routine use of probiotics in the state neonatal units. The third option is for each institution to develop its own on-site expertise within the federal regulatory guidelines. In countries such as the USA, where probiotics ('intended to use to diagnose, cure, mitigate, treat or prevent disease and affecting structure or function of the body') are registered as drugs rather than food supplements, the regulatory restrictions on the access to probiotics will be considerable $[129,130]$. Substantial delay in access to probiotics is inevitable in such countries if phase I, II and III studies are to be conducted before probiotics can be made easily available $[131,132]$. Defining probiotics as 'foods for specialised health use' as in Japan may overcome these difficulties $[133,134]$. It is important to note that, although the regulatory restrictions will be more stringent if probiotics are regulated as drugs, the regulations will then at least be clear and consistently applied, and once licensed, probiotics will potentially be more accessible to consumers and physicians. Thus, in the longer term it may actually be in the patients' interest for probiotics to be regulated as drugs under some circumstances.

We believe that with cooperation between government, industry, scientists, and the International Probiotics Association, any one of these strategies could be easily adopted to increase the availability of high-quality probiotics if there is a political will to do so.

\section{Other potentially useful strategies}

Owing to the development of aberrant gut flora and delayed colonisation by normal commensal strains in preterm neonates, early preferential feeding with breast milk and minimising exposure to antibiotics are crucial to optimise the benefits of probiotic supplementation [52]. Neonates given antibiotics at birth have been reported to retain abnormal microbial flora 4 weeks later, indicating the damaging effect of these agents [135]. Strategies for preventing sepsis are also crucial in optimising the benefits of probiotic supplementation, as sepsis needs treatment with antibiotics (anti-probiotics) [136]. The benefits of a standardised feeding protocol must not be forgotten if prevention of NEC and facilitation of enteral nutrition is the goal [137-142]. Such a protocol will help in evaluation of the efficacy of probiotics in presence of different feeding policies. For neonatal units with donor milk banks, the effect of pasteurisation on breast-milk probiotics needs to be studied, given the thermal sensitivity of probiotic strains [143]. Breast-milk oligosaccharides are not affected by pasteurisation [144].

\section{Data monitoring}

Probiotic supplementation is a new development in neonatal intensive care. Hence, high-quality data monitoring is essential to evaluate population outcomes in this high-risk cohort. Monitoring data during routine use is similar to post-marketing surveillance, which has a higher rate of detection of AEs (including rare ones) [145], and is helpful in comparing the benefits and risks 
in different populations with different management practices. Such data are essential to evaluate the effects of the intervention at a local level, and for planning future research. It is often a requirement of regulatory agencies such as the TGA when an unlicensed drug is used. The need for post-marketing surveillance has been emphasised by expert committees [146]. Collaboration between regional neonatal networks is crucial for linkage of databases.

\section{Information for parents}

Based on the current evidence, parents are unlikely to refuse probiotics, an intervention that substantially reduces the incidence of death and life-threatening diseases such as NEC $[11,14]$. Because of the lack of significant experience with probiotics, especially in extremely preterm neonates, and the currently unanswered questions surrounding this intervention, it is important to ensure that parents are well informed about the benefits and potential AEs, both short- and long-term. Honesty, clarity and transparency in sharing information with the parents, and respect for their autonomy are crucial. Informed consent may be required until sufficient experience has been obtained to provide probiotics as a routine therapy without hesitation. Continued vigilance, equivalent to post-marketing surveillance, and uniform reporting are necessary to gain more data and confidence with probiotic supplementation.

\section{Role of placebo-controlled trials}

The sum of the current evidence supports our view that the role of placebo-controlled trials is necessary only for the evaluation of new strains. From the purist's point of view, a large, definitive, placebo-controlled trial may be justified for ELBW neonates in a setting of low baseline risk, but given the current evidence and the difficulties in obtaining fully informed consent from parents, successful completion of such a trial in a realistic time frame will be difficult. We have pointed out that the issue of reproducibility in different settings has been addressed adequately. Placebo-controlled trials are not justified purely for evaluating the frequency and consequences of cross-contamination. Allowing access to a known, clinically effective, probiotic product also cannot be the justification for such a trial, especially when special regulatory schemes allow access to a life-saving intervention. For addressing other important issues such as defining the optimum intervention (which probiotic (s), what dose and timing), and assessing microbial adaptations and ecological consequences, interactions with other preventive interventions and the effect of probiotics on early development, other types of study designs such as head to head trials (comparing different products or protocols), cluster randomised and factorial trials, cohort studies and long-term follow-up studies are more suitable than placebo-controlled trials. The frequency of cross-contamination in the placebo arm of a RCT is important in this context. As for understanding the mechanisms of the benefits of probiotics in the prevention of NEC, it is important to note that the pathogenesis of NEC remains poorly understood despite extensive research for over three decades and that there are multiple pathways by which probiotic(s) can provide benefit [63]. There is a wide range of possible mechanisms that need further investigation, and several clinical observations that cannot be satisfactorily explained at the cellular level [75]. A large number of the mechanisms cannot be measured easily in humans for ethical or feasibility reasons (for example, access to tissue specimens).

\section{Advancing knowledge by further research while not denying probiotics to preterm neonates}

High-quality definitive RCTs comparing issues such as low versus high doses, single versus multiple strains, live versus killed probiotic organisms $[118,147]$, whole probiotics versus probiotic components $[148,149]$, probiotics versus prebiotics, probiotics versus synbiotics, commencing supplementation 'very early' (starting on day 1 of life if the severity of initial illness is not restrictive) versus starting 'as early as possible' (ready for enteral feeds), and 'enteral plus topical' (oral spray) versus 'only enteral' supplementation, will advance the knowledge in this area. A clear understanding of the benefits and risks of probiotics will also be facilitated by the advantages of prospective and robust data collection during such research. Long-term issues such as NDI, development of allergy, sensitisation and altered immune responses also need to be monitored. The significance of exposure of preterm neonates to lactose, dextrin and cornstarch, which are used as carriers or substrates in probiotic products, needs to be evaluated [150].

\section{Accessing probiotic products for research versus routine use}

Accessing a probiotic product (Table 2) may be relatively easy in research rather than routine use, at least until the regulatory issues are clarified. In Australia, importing a probiotic is possible with clinical trial notification approval from the TGA and a licence to import a biological product from the Australian Quarantine and Inspection Services. It is also possible in Australia, with the local approval of the Drug and Therapeutics Committee and endorsement by the TGA of named clinicians as authorised prescribers, to obtain a probiotic under a special access scheme. A similar scheme is possible in the UK. For a new product or strain, a very 
Table 3 Specific recommendations for major clinical decisions

\begin{tabular}{|c|c|c|}
\hline \multicolumn{2}{|l|}{ Specific recommendations } & \multirow{2}{*}{$\begin{array}{l}\text { LOE }^{\text {a }} \text { [reference] } \\
\text { I }[14] ; \text { II }[55,56,60] ; \\
\text { III-[3,15] }\end{array}$} \\
\hline Selection of strains & $\begin{array}{l}\text { Combination containing Lactobacillus and at least one Bifidobacterium species is preferable. } \\
\text { Lactobacillus GG alone may not be effective }\end{array}$ & \\
\hline Dose & $3 \times 10^{9}$ organisms per day, preferably in a single dose & | [14]; || [55,56,60] \\
\hline When to start? & When the neonate is ready for enteral feeds, preferably within first 7 days of life & $\begin{array}{l}\text { I }[14] ; \text { || }[55,56,60] ; \\
\text { III }[3,15]\end{array}$ \\
\hline How long to continue? & At least until 35 weeks corrected age, or discharge & ॥ $[55,56,60]$ \\
\hline $\begin{array}{l}\text { Supplementation during } \\
\text { acute illness }\end{array}$ & $\begin{array}{l}\text { Stopping the supplementation during an acute illness such as sepsis, NEC }{ }^{\mathbf{b}} \text { or perinatal asphyxia } \\
\text { may be safe }\end{array}$ & IV [94-98] \\
\hline
\end{tabular}

aLevel of evidence.

${ }^{b}$ Necrotising enterocolitis.

thorough independent QA/QC process is needed before using it in this high-risk population. Small placebo-controlled trials (rather than observational studies) will be important to rigorously assess and confirm the ability of the new strains to colonise the preterm gut if the product is to be adopted for routine use. Even minor variations in the manufacturing process can compromise the safety and efficacy of the product $[51,67,112,151]$.

\section{Conclusion}

We have provided evidence-based guidelines (Table 3; Table 4) for the use of probiotics in preterm neonates, as we believe that the current evidence justifies routine use of this intervention [18]. These guidelines will also be helpful for optimal use of probiotics in research settings. We believe that probiotics should be offered routinely to all high-risk preterm neonates, taking into account the unaddressed issues. The best way forward could be to offer these products routinely but still within a research framework to cover the current gaps in knowledge [28]. It is important to note that most of the unaddressed issues can be easily resolved by studies not requiring a placebo.

The benefits of probiotics may not be dramatic in neonatal units with a low incidence of all-cause mortality and definite NEC in preterm neonates for various

Table 4 Guidelines for other clinical and non-clinical issues ${ }^{a}$

\begin{tabular}{|c|c|}
\hline Guidelines & References \\
\hline 1. Starting dose for ELBW ${ }^{\mathbf{b}}$ neonates: $1.5 \times 10^{9} \mathrm{cfu}$ day $^{\mathbf{c}}$ until reaching $50-60 \mathrm{ml} / \mathrm{kg} /$ day feeds & [84] and authors' opinion \\
\hline 2. Osmotic load: solution should be diluted to keep the osmolality below $600 \mathrm{mOsm} / \mathrm{L}$ & {$[86,87]$} \\
\hline 3. Diluent: sterile water or breast milk & Authors' opinion \\
\hline 4. Volume for administration: 1 to $1.5 \mathrm{ml}$ per dose & [86] and authors' opinion \\
\hline $\begin{array}{l}\text { 5. Clinical monitoring: patients should be monitored for intolerance (abdominal distension, diarrhea, vomiting), } \\
\text { probiotic sepsis, and adverse effects (flatulence, loose stools) of additives such as prebiotic oligosaccharides. }\end{array}$ & $\begin{array}{l}\text { [95-101] and manufacturer } \\
\text { recommendation }\end{array}$ \\
\hline $\begin{array}{l}\text { 6. Ongoing laboratory surveillance: Expertise in taxonomy confirmation (16S rRNA sequencing and PFGE }{ }^{\mathbf{d}} \text {, ruling } \\
\text { out contaminants, recovering probiotic strains at low inoculums from sterile sites, familiarity with the Gram stain } \\
\text { and phenotypic appearance of probiotics, and monitoring for antibiotic susceptibility/resistance and cross- } \\
\text { contamination are crucial. }\end{array}$ & {$[107]$} \\
\hline 7. Cold chain: maintenance of cold chain should be checked. Refrigerate at 4 to $10^{\circ} \mathrm{C}$ & Manufacturer recommendation \\
\hline 8. Product stability: stability should be checked by regular microbiological tests & {$[51,67,112,151]$} \\
\hline 9. Leftover solution should be discarded after giving small doses as it may get contaminated & Manufacturer recommendation \\
\hline $\begin{array}{l}\text { 10. Regulatory issues: importing may be easier for research than for clinical use. National regulations on drugs } \\
\text { and food supplements and customs quarantine guidelines should be checked }\end{array}$ & {$[131,132]$} \\
\hline $\begin{array}{l}\text { 11. Data monitoring: high-quality data monitoring and collaboration between regional neonatal networks is } \\
\text { crucial for monitoring outcomes at a population level }\end{array}$ & {$[145,146]$} \\
\hline $\begin{array}{l}\text { 12. Information for parents: parents should be kept well informed about benefits and adverse effects, including } \\
\text { the possibility of cross-contamination }\end{array}$ & {$[18,24]$} \\
\hline $\begin{array}{l}\text { 13. Other potentially useful strategies: early preferential use of breast milk, strategies for prevention of sepsis, } \\
\text { standardised feeding protocols, avoidance of undue prolonged exposure to antibiotic }\end{array}$ & {$[137-142]$} \\
\hline \multicolumn{2}{|c|}{$\begin{array}{l}\text { a Level of evidence was applicable to specific recommendations for clinical issues (Table } 3 \text { ) and not to other guideline components discussed in Table } 4 \text { above. } \\
{ }^{b} \text { Extremely low birth weight. }\end{array}$} \\
\hline
\end{tabular}


reasons. Investigators have suggested that nutritional outcomes may be appropriate for probiotic research in such neonatal units, because of the beneficial effects of probiotics on the gastrointestinal tract $[9,14,62,136-138]$.

Current evidence is inadequate in some areas of probiotic supplementation. We have erred on the side of safety in suggesting guidelines in these areas, taking into consideration the basic principle: first, do no harm. We wish to emphasise that 'routine' does not equate to 'blind' use of probiotics, a potentially powerful but double-edged weapon in this high-risk population [19]. As the debate around routine use of probiotics in preterm neonates continues, countries such as Denmark have already issued guidelines for use of probiotics in preterm neonates [152]. If prevention of death and disease and facilitation of nutrition is the goal, relying on a package of potentially better practices rather than on probiotics alone is essential $[153,154]$.

\section{Additional material}

Additional file 1: Appendix I - PubMed search results. This appendix includes the results of PubMed (1966 to October 2010) search.

Additional file 2: Appendix I - EMBASE search results. This appendix includes the results of the EMBASE (1980 to October 2010) search.

\section{Acknowledgements}

This project was funded by the Telethon Channel 7 Trust.

\section{Author details}

${ }^{1}$ Department of Neonatal Paediatrics, Nepean Hospital Sydney, Sydney, Australia. ${ }^{2}$ University of Sydney, Australia Sydney, Australia. ${ }^{3}$ Department of Neonatal Paediatrics, KEM Hospital for Women, Perth, Australia. ${ }^{4}$ Department of Neonatal Paediatrics, Princess Margaret Hospital for Children, Perth, Australia. ${ }^{5}$ University of Western Australia, Perth, Australia. ${ }^{6}$ PathWest Laboratory Medicine, WA, USA.

\section{Authors' contributions}

Dr D participated in the literature search, selected relevant papers and contributed to writing the manuscript. Dr R also conducted an independent literature search, selected relevant papers and contributed to writing the manuscript. Dr D and Dr R applied the levels of evidence independently and finalised them together, and resolved inconsistencies with discussion. Dr P was responsible for the concept, design and writing of the final version of the manuscript, which was seen and approved by all authors. Dr AK is an expert microbiologist, and contributed towards the relevant sections of the manuscript.

\section{Competing interests}

The authors declare that they have no competing interests.

Received: 28 June 2011 Accepted: 2 August 2011

Published: 2 August 2011

\section{References}

1. Lin PW, Stoll BJ: Necrotising enterocolitis. Lancet 2006, 368:1271-1283.

2. Cotten $C M, O h W, M c D o n a l d ~ S$ : Prolonged hospital stay for extremely premature infants: risk factors, center differences, and the impact of mortality on selecting a best-performing center. J Perinatol 2005, 25:650-655.
3. Wales PW, Christison-Lagay ER: Short bowel syndrome: epidemiology and etiology. Semin Pediatr Surg 2010, 19:3-9.

4. Salvia G, Guarino A, Terrin G, Cascioli C, Paludetto R, Indrio F, Lega L, Fanaro S, Stronati M, Corvaglia L, Tagliabue P, De Curtis M, Working Group on Neonatal Gastroenterology of the Italian Society of Pediatric Gastroenterology, Hepatology and Nutrition: Neonatal onset intestinal failure: an Italian multicenter study. J Pediatr 2008, 153:674-676.

5. Schulzke SM, Deshpande GC, Patole SK: Neurodevelopmental outcome of very low birth weight infants with necrotizing enterocolitis - A systematic review of observational studies. Arch of Pediatr Adolesc Med 2007, 161:583-590.

6. Hintz SR, Kendrick DE, Stoll BJ, Vohr BR, Fanaroff AA, Donovan EF, Poole WK, Blakely ML, Wright L, Higgins R, NICHD Neonatal Research Network: Neurodevelopmental and growth outcomes of extremely low birth weight infants after necrotizing enterocolitis. Pediatrics 2005, 115:696-703.

7. Stoll BJ: Epidemiology of necrotizing enterocolitis. Clin Perinatol 1994, 21:205-218.

8. Patole S: Prevention and treatment of necrotising enterocolitis in preterm neonates. Early Hum Dev 2007, 83:635-642.

9. Deshpande G, Rao S, Patole S: Probiotics for prevention of necrotising enterocolitis in preterm neonates with very low birthweight: a systematic review of randomised controlled trials. Lancet 2007, 369:1614-1620.

10. Barclay AR, Stenson B, Simpson JH, Weaver LT, Wilson DC: Probiotics for necrotizing enterocolitis: a systematic review. J Pediatr Gastroenterol Nutr 2007, 45:569-576.

11. Alfaleh K, Bassler D: Probiotics for prevention of necrotizing enterocolitis in preterm infants. Cochrane Database Syst Rev 2008, 1:CD005496.

12. Deshpande G, Rao S, Patole S: Probiotics for prevention of necrotising enterocolitis in preterm neonates with very low birthweight: a systematic review of randomised controlled trials. In Year book of Pediatrics. Volume Chapter 14. Edited by: Newborn Stockman JA III. Elsevier Mosby; 2009:441-443

13. Indrio F, Riezzo G, Raimond F, Bisceglia M, Cavallo L, Francavilla R: The effects of probiotics on feeding tolerance, bowel habits, and gastrointestinal motility in preterm newborns. In The Year book of Neonatal and Perinatal medicine Gastroenterology and nutrition. Volume Chapter 14. Edited by: Fanaroff AA, Benitz W, Neu J, Papille L. Elsevier Mosby; 2009:138-139.

14. Deshpande G, Rao S, Patole S, Bulsara M: Updated meta-analysis of probiotics for preventing necrotizing enterocolitis in preterm neonates. Pediatrics 2010, 125:921-930.

15. Satoh $Y$, Shinohara K, Umezaki H, Shoji H, Satoh H, Ohtsuka Y, Shiga S, Nagata S, Shimizu T, Yamashiro Y: Bifidobacteria prevents necrotising enterocolitis and infection. Int J Probiot Prebiot 2007, 2:149-154.

16. Chou IC, Kuo HT, Chang JS, Wu SF, Chiu HY, Su BH, Lin HC: Lack of effects of oral probiotics on growth and neurodevelopmental outcomes in preterm very low birth weight infants. J Pediatr 2010, 156:393-396.

17. Romeo MG, Romeo DM, Trovato L, Oliveri S, Palermo F, Cota F, Betta P: Role of probiotics in the prevention of the enteric colonization by Candida in preterm newborns: incidence of late-onset sepsis and neurological outcome. J Perinatol 2011, 31:63-69.

18. Tarnow-Mordi WO, Wilkinson D, Trivedi A, Brok J: Probiotics reduce allcause mortality and necrotizing enterocolitis: it is time to change practice. Pediatrics 2010, 125:1068-1070.

19. Soll RF: Probiotics: are we ready for routine use? Pediatrics 2010, 125:1071-1072.

20. Neu J, Shuster J: Nonadministration of routine probiotics unethicalreally? Pediatrics 2010, 126:e740-e741, Author reply e743-745.

21. Garland MSuzanne, Jacobs S, Tobin J, on behalf of Proprems study group: A cautionary note on instituting probiotics into routine clinical care for premature infants. Pediatrics 2010, 126:e741-e742.

22. Beattie LM, Hansen R, Barclay A: Probiotics for preterm infants: confounding features warrant caution. Pediatrics 2010, 126:e742-e743.

23. Millar M, Wilks M, Fleming P, Costeloe K: Should the use of probiotics in the preterm be routine? Arch Dis Child Fetal Neonatal Ed 2010.

24. Deshpande G, Rao S, Patole S, Bulsara M: Probiotics for preterm neonates - time to acknowledge the elephant in the room and call the parents. Pediatrics 2010, 126:e744-e745.

25. Caplan MS, Miller-Catchpole R, Kaup S, Russell T, Lickerman M, Amer M, Xiao $Y$, Thomson R Jr: Bifidobacterial supplementation reduces the 
incidence of necrotizing enterocolitis in a neonatal rat model. Gastroenterology 1999, 117:577-583.

26. Hoyos AB: Reduced incidence of necrotising enterocolitis associated with enteral administration of Lactobacillus acidophilus and Bifidobacterium infantis to neonates in an intensive care unit. Int J Infect Dis 1999, 3:197-202.

27. Luoto R, Matomäki J, Isolauri E, Lehtonen L: Incidence of necrotizing enterocolitis in very-low-birth-weight infants related to the use of Lactobacillus GG. Acta Paediatr 2010, 99:1135-1138, Erratum in: Acta Paediatr 2011, 100:631.

28. Luoto $R$, Isolauri $E$, Lehtonen L: Safety of Lactobacillus GG probiotic in infants with very low birth weight: twelve years of experience. Clin Infect Dis 2010, 50:1327-1328.

29. Moher D, Liberati A, Tetzlaff J, Altman DG, The PRISMA Group: Preferred Reporting items for systematic reviews and meta-analyses: The PRISMA Statement. PLoS Med 2009, 6:e1000097.

30. Gugiu PC, Gugiu MR: A critical appraisal of standard guidelines for grading levels of evidence. Eval Health Prof 2010, 33:233-255.

31. Berger WW, Knoll D: Levels of evidence: further insight on Gugiu and Gugiu. Eval Health Prof 2011, 34:124-126, Discussion: 127-130.

32. Petrisor BA, Keating J, Schemitsch E: Grading the evidence: levels of evidence and grades of recommendation. Injury 2006, 37:321-327.

33. Merlin T, Weston A, Tooher R: Extending an evidence hierarchy to include topics other than treatment: revising the Australian 'levels of evidence'. BMC Med Res Methodol 2009, 9:34.

34. Atkins $D$, Best $D$, Briss PA, Eccles M, Falck-Ytter Y, Flottorp $S$, Guyatt GH, Harbour RT, Haugh MC, Henry D, Hill S, Jaeschke R, Leng G, Liberati A, Magrini N, Mason J, Middleton P, Mrukowicz J, O'Connell D, Oxman AD, Phillips B, Schünemann HJ, Edejer TT, Varonen $H$, Vist GE, Williams JW Jr, Zaza S, GRADE Working Group: Grading quality of evidence and strength of recommendations. BMJ 2004, 328:1490-1494.

35. Upshur RE: Are all evidence-based practices alike? Problems in the ranking of evidence. CMAJ 2003, 169:672-673.

36. Deeks JJ, Dinnes J, D'Amico R, Sowden AJ, Sakarovitch C, Song F, Petticrew M, Altman DG: International Stroke Trial Collaborative Group; European Carotid Surgery Trial Collaborative Group. Health Technol Assess 2003, 7:iii-x, 1-173.

37. Stang A: Critical evaluation of the Newcastle-Ottawa scale for the assessment of the quality of nonrandomized studies in meta-analyses. Eur J Epidemiol 2010, 25:603-605.

38. Cochrane Handbook for Systematic Reviews of Interventions. [http:// www.cochrane-handbook.org/], (accessed March 2011).

39. Jadad AR, Moore RA, Carroll D, Jenkinson C, Reynolds DJ, Gavaghan DJ, McQuay HJ: Assessing the quality of reports of randomized clinical trials: Is blinding necessary? Controlled Clin Trials 1996, 17:1-12

40. Salminen S, Isolauri E: Intestinal colonisation, microbiota and probiotics. J Pediatr 2006, 149:S115-S120.

41. Harmsen HJ, Wildeboer-Veloo AC, Raangs GC, Wagendorp AA, Klijn N, Bindels JG, Welling GW: Analysis of intestinal flora development in breast-fed and formula-fed infants by using molecular identification and detection methods. J Pediatr Gastroenterol Nutr 2000, 30:61-67.

42. Mshvildadze M, Neu J: Probiotics and prevention of necrotizing enterocolitis. Early Hum Dev 2009, 85(Suppl 10):S71-74.

43. Ohashi $Y$, Ushida K: Health-beneficial effects of probiotics: Its mode of action. Animal Science Journal 2009, 80:361-371.

44. Rautava S, Walker WA: Probiotics. In Nutrition and Health, Probiotics in Pediatric Medicine. Edited by: Michail S, Sherman MC. Humana Press NJ USA; 2009:41-52.

45. Morelli L: In vitro selection of probiotic lactobacilli: a critical appraisal. Curr Issues Intest Microbiol 2000, 1:59-67.

46. Kosin B, Rakshit S: Microbial and processing criteria for production of probiotics: a review. Food Technol Biotechnol 2006, 44:371-379.

47. Saavendra JM: Use of probiotics in pediatrics: rationale, mechanisms of action, and practical aspects. Nutr Clin Pract 2007, 22:351-365.

48. Crittenden R, Bird AR, Gopal P, Henriksson A, Lee YK, Playne MJ: Probiotic research in Australia, New Zealand and the Asia-Pacific Region. Current Pharmaceutical Design 2005, 11:37-53.

49. Prasad J, Gill HS, Smart J, Gopal PK: Selection and characterisation of Lactobacillus and Bifidobacterium strains for use as probiotics. Int Dairy J 1998, 8:993-1002.
50. Dunne C, O'Mahony L, Murphy L, Thornton G, Morrissey D, O'Halloran S, Feeney M, Flynn S, Fitzgerald G, Daly C, Kiely B, O'Sullivan GC, Shanahan F, Collins JK: In vitro selection criteria for probiotic bacteria of human origin: correlation with in vivo findings. Am J Clin Nutr 2001, 73(Suppl 2):386S-3925.

51. Salminen S, Collado MC, Isolauri E, Gueimonde M: Microbial-host interactions: selecting the right probiotics and prebiotics for infants. Nestle Nutr Workshop Ser Pediatr Program 2009, 64:201-13, Discussion: 213217, 251-257.

52. Kitajima H, Sumida Y, Tanaka R, Yuki N, Takayama H, Fujimura M: Early administration of Bifidobacterium breve to preterm neonates: randomised control trial. Arch Dis Child 1997, 76:F101-107.

53. Dani C, Biadaioli R, Bertini G, Martelli E, Rubaltelli FF: Probiotics feeding in prevention of urinary tract infection, bacterial sepsis and necrotizing enterocolitis in preterm neonates. A prospective double-blind study. Biol Neonate 2002, 82:103-108.

54. Costalos C, Skouteri V, Gounaris A, Sevastiadou S, Triandafilidou A, Ekonomidou C, Kontaxaki F, Petrochilou V: Enteral feeding of premature neonates with Saccharomyces boulardii. Early Hum Dev 2003, 74:89-96.

55. Bin-Nun A, Bromiker R, Wilschanski M, Kaplan M, Rudensky B, Caplan M, Hammerman C: Oral probiotics prevent necrotizing enterocolitis in very low birth weight neonates. J Pediatr 2005, 147:192-196.

56. Lin HC, Su BH, Chen AC, Lin TW, Tsai CH, Yeh TF, Oh W: Oral probiotics reduce the incidence and severity of necrotizing enterocolitis in very low birth weight neonates. Pediatrics 2005, 115:1-4.

57. Manzoni P, Mostert M, Leonessa ML, Priolo C, Farina D, Monetti C, Latino MA, Gomirato G: Oral supplementation with Lactobacillus casei subspecies rhamnosus prevents enteric colonisation by candida species in preterm neonates: a randomised study. Clin Infect Dis 2006, 42:1735-1742

58. Mohan R, Koebnick C, Schildt J, Schmidt S, Mueller M, Possner M, Radke M, Blaut M: Effects of Bifidobacterium lactis Bb12 supplementation on intestinal microbiota of preterm neonates: A double placebo controlled, randomised study. J Clin Microbiol 2006, 44:4025-4031.

59. Stratiki Z, Costalos C, Sevastiadou S, Kastanidou O, Skouroliakou M, Giakoumatou A, Petrohilou V: The effect of a bifidobacteria supplemented bovine milk on intestinal permeability of preterm infants. Early Hum Dev 2007, 83:575-579.

60. Lin HC, Hsu CH, Chen HL, Chung MY, Hsu JF, Lien Rl, Tsao LY, Chen CH, Su BH: Oral probiotics prevent necrotizing enterocolitis in very low birth weight preterm infants: a multicenter, randomized, controlled trial. Pediatrics 2008, 122:693-700.

61. Samanta M, Sarkar M, Ghosh P, Ghosh J, Sinha M, Chatterjee S: Prophylactic probiotics for prevention of necrotizing enterocolitis in very low birth weight newborns. J Trop Pediatr 2009, 55:128-131.

62. Rougé $C$, Piloquet $H$, Butel $M J$, Berger $B$, Rochat $F$, Ferraris $L$, Des Robert $C$, Legrand $A$, de la Cochetière MF, N'Guyen JM, Vodovar M, Voyer M, Darmaun D, Rozé JC: Oral supplementation with probiotics in very-lowbirth-weight preterm infants: a randomized, double-blind, placebocontrolled trial. Am J Clin Nutr 2009, 89:1828-1835.

63. Claud EC: Neonatal necrotizing enterocolitis-inflammation and intestinal immaturity. Antiinflamm Antiallergy Agents Med Chem 2009, 8:248-259.

64. Allen SJ, Martinez EG, Gregorio GV, Dans LF: Probiotics for treating acute infectious diarrhoea. Cochrane Database Syst Rev 2010, 11:CD003048.

65. Vissers YM, Snel J, Zuurendonk PF, Smit BA, Wichers HJ, Savelkoul HF: Differential effects of Lactobacillus acidophilus and Lactobacillus plantarum strains on cytokine induction in human peripheral blood mononuclear cells. FEMS Immunol Med Microbiol 2010, 59:60-70.

66. Agrawal R, Sharma N, Chaudry R, Deorari A, Paul VK, Gewolb IH, Panigrahi P. Effects of oral lactobacillus GG on enteric microflora in low birth weight neonates. J Pediatr Gastroenterol Nutr 2003, 36:397-402.

67. Salminen S, Nybom S, Meriluoto J, Collado MC, Vesterlund S, El-Nezami H: Interaction of probiotics and pathogens-benefits to human health? Curr Opin Biotechnol 2010, 21:157-167.

68. Timmerman HM, Koning CJM, Mulder L, Rombouts FM, Beynen AC: Monostrain, multistrain and multispecies probiotics - a comparison of functionality and efficacy. Int J Food Microbiol 2004, 96:219-233.

69. Gardiner GE, Casey PG, Casey G, Lynch PB, Lawlor PG, Hill C, Fitzgerald GF, Stanton C, Ross RP: Relative ability of orally administered Lactobacillus murinus to predominate and persist in the porcine gastrointestinal tract. Appl Environ Microbiol 2004, 70:1895-1906. 
70. Vinderola CG, Mocchiutti P, Reinheimer JA: Interactions among lactic acid starter and probiotic bacteria used for fermented dairy products. J Dairy Sci 2002, 85:721-729.

71. Famularo G, De Simone C, Matteuzzi D, Pirovano F: Traditional and high potency probiotic preparations for oral bacteriotherapy. Bio Drugs 1999, 12:455-470.

72. Sanders ME, Huius in't Veld JHJ: Bringing a probiotic containing functional food to the market: microbiological, product, regulatory and labelling issues. Antonie Van Leeuwenhoek 1999, 76:293-315.

73. Chapman CM, Gibson GR, Rowland I: Health benefits of probiotics: are mixtures more effective than single strains? Eur J Nutr 2011, 50:1-17.

74. Savage DC: Microbial ecology of the gastrointestinal tract. Annu Rev Microbiol 1977, 31:107-133.

75. Current level of consensus on probiotic science - Report of an expert meeting - London, 23 November 2009. [http://www.isapp.net/docs/ Report_of_an_expert_meeting-V7MES.pdf], Accessed on April 20, 2011.

76. Szajewska H, Guandalini S, Morelli L, Van Goudoever JB, Walker A: Effect of Bifidobacterium animalis subsp lactis supplementation in preterm infants: A systematic review of randomised controlled trials. J Pediatr Gastroenterol Nutr 2010, 51:203-209.

77. Collado MC, Meriluoto J, Salminen S: Development of new probiotics by strain combinations: is it possible to improve the adhesion to intestinal mucus? J Dairy Sci 2007, 90:2710-2716.

78. Lewis SJ, Freedman AR: Review article: the use of biotherapeutic agents in the prevention and treatment of gastrointestinal disease. Aliment Pharmacol Ther 1998, 12:807-822.

79. Martin CR, Walker AW: Probiotics: role in pathophysiology and prevention in necrotizing enterocolitis. Semin Perinatol 2008, 32:127-137.

80. Galdeano CM, Perdigón G: Role of viability of probiotic strains in their persistence in the gut and in mucosal immune stimulation. $J \mathrm{Appl}$ Microbiol 2004, 97:673-681.

81. Shah NP, Ali JF, Ravula RK: Populations of L. acidophilus, Bifidobacterium spp., and Lactobacillus casei in commercial fermented milk products. Biosci Microflora 2000, 19:35-39.

82. Sanders ME, Akkermans LM, Haller D, Hammerman C, Heimbach J, Hörmannsperger G, Huys G, Levy DD, Lutgendorff F, Mack D, Phothirath $P$ Solano-Aguilar G, Vaughan E: Safety assessment of probiotics for human use. Gut Microbes 2010, 1:164-185.

83. Sarker SA, Fuchs GJ: The role of probiotics in treatment and prevention of infectious diarrhea. In Nutrition and Health, Probiotics in Pediatric Medicine. Edited by: Michail S, Sherman PM. Humana Press, Springer; 2009:147-165.

84. Patole S: Strategies for prevention of feed intolerance in preterm neonates: a systematic review. J Matern Fetal Neonatal Med 2005, 18:67-76.

85. Kerac M, Bunn J, Seal A, Thindwa M, Tomkins A, Sadler K, Bahwere P, Collins S: Probiotics and prebiotics for severe acute malnutrition (PRONUT study): a double-blind efficacy randomised controlled trial in Malawi. Lancet 2009, 374:136-144.

86. Patole SK, de Klerk N: Impact of standardised feeding regimens on incidence of neonatal necrotising enterocolitis: a systematic review and meta-analysis of observational studies. Arch Dis Child Fetal Neonatal Ed 2005, 90:F147-51.

87. Williams AF: Role of feeding in necrotising enterocolitis. Semin Neonatol 1997, 2:263-271.

88. White $\mathrm{KC}$, Harkavy KL: Hypertonic formula resulting from added oral medications. Am J Dis Child 1982, 136:931-933.

89. Clark P, Robinson MJ: Thickening milk feeds may cause necrotising enterocolitis. Arch Dis Child fetal Neonatal Ed 2004, 89:F280.

90. Pereira-da-Silva L, Henriques G, Videira-Amaral JM, Rodrigues R, Ribeiro L, Virella D: Osmolality of solutions, emulsions and drugs that may have a high osmolality: aspects of their use in neonatal care. J Matern Fetal Neonatal Med 2002, 11:333-338.

91. Conroy ME, Shi HN, Walker WA: The long-term health effects of neonatal microbial flora. Curr Opin Allergy Clin Immunol 2009, 9:197-201.

92. Leaf A, Dorling J, Kempley S, McCormick K, Mannix P, Brocklehurst P: ADEPT - Abnormal Doppler Enteral Prescription Trial. BMC Pediatr 2009, 9:63.

93. Goldin BR, Gorbach SL, Saxelin M, Barakat S, Gualtieri L, Salminen S: Survival of Lactobacillus species (strain GG) in human gastrointestinal tract. Dig Dis Sci 1992, 37:121-128.
94. Boyle RJ, Robins-Browne RM, Tang ML: Probiotic use in clinical practice: what are the risks? Am J Clin Nutr 2006, 83:1256-1264.

95. Thompson C, McCarter YS, Krause PJ, Herson VC: Lactobacillus acidophilus sepsis in a neonate. J Perinatol 2001, 21:258-260.

96. Broughton RA, Gruber WC, Haffar AA, Baker CJ: Neonatal meningitis due to lactobacillus. Pediatr Infect Dis 1983, 2:382-384.

97. Perapoch J, Planes AM, Querol A, López V, Martínez-Bendayán I, Tormo R, Fernández F, Peguero G, Salcedo S: Fungemia with Saccharomyces cerevisiae in two newborns, only one of whom had been treated with ultra-levure. Eur J Clin Microbiol Infect Dis 2000, 19:468-470.

98. Ohishi A, Takahashi S, Ito Y, Ohishi Y, Tsukamoto K, Nanba Y, Ito N, Kakiuchi S, Saitoh A, Morotomi M, Nakamura T: Bifidobacterium septicemia associated with postoperative probiotic therapy in a neonate with omphalocele. J Pediatr 2010, 156:679-681.

99. Besselink MGH, van Santvoort HC, Buskens $E$, Boermeester MA, van Goor $H$, Timmerman HM, Nieuwenhuijs VB, Bollen TL, van Ramshorst B, Witteman BJ, Rosman C, Ploeg RJ, Brink MA, Schaapherder AF, Dejong CH, Wahab PJ, van Laarhoven CJ, van der Harst E, van Eijck CH, Cuesta MA, Akkermans LM, Gooszen HG, Dutch Acute Pancreatitis Study Group: Probiotic prophylaxis in predicted severe acute pancreatitis: a randomised, double-blind, placebo controlled trial. Lancet 2008, 371:651-659.

100. Chatterjee S, Fraser J: Probiotics: sorting the evidence from the myths. MJA 2008, 189:182.

101. Besselink MG, van Santvoort HC, Renooij W, de Smet MB, Boermeester MA, Fischer K, Timmerman HM, Ahmed Ali U, Cirkel GA, Bollen TL, van Ramshorst B, Schaapherder AF, Witteman BJ, Ploeg RJ, van Goor H, van Laarhoven CJ, Tan AC, Brink MA, van der Harst E, Wahab PJ, van Eijck CH, Dejong $\mathrm{CH}$, van Erpecum KJ, Akkermans LM, Gooszen HG, Dutch Acute Pancreatitis Study Group: Intestinal barrier dysfunction in a randomized trial of a specific probiotic composition in acute pancreatitis. Dutch Acute Pancreatitis Study Group. Ann Surg 2009, 250:712-719.

102. Srinivasjois R, Rao S, Patole S: Prebiotic supplementation of formula in preterm neonates: a systematic review and meta-analysis of randomised controlled trials. Clin Nutr 2009, 28:237-242.

103. Salminen MK, Rautelin H, Tynkkynen S, Poussa T, Saxelin M, Valtonen V, Järvinen A: Lactobacillus bacteremia, clinical significance, and patient outcome, with special focus on probiotic L. rhamnosus GG. Clin Infect Dis 2004, 38:62-69.

104. Kunz AN, Noel JM, Firchok MP: Two cases of Lactobacillus bacteremia during probiotic treatment of short gut syndrome. J Pediatr Gastroenterol Nutr 2004, 38:457-458.

105. Land MH, Rouster-Stevens K, Woods CHR, Cannon ML, Cnota J, Shetty AK: Lactobacillus sepsis associated with probiotic therapy. Pediatrics 2005, 115:178-181.

106. Mahlen SD, Clarridge JE: Site and clinical significance of Alloscardovia omnicolens and Bifidobacterium species isolated in the clinical laboratory. J Clin Microbiol 2009, 47:3289-3293.

107. Syndman DR: The safety of probiotics. Clin Infect Dis 2008, 46:S104-S111.

108. Costeloe K: PiPS: trial of probiotic administered early to prevent infection and necrotising enterocolitis protocol-version. 3.1.[http://www.hta.ac.uk/ protocols/200505010004.pdf], Accessed October 20, 2010.

109. Mayrhofer S, Domig KJ, Mair C, Zitz U, Huys G, Kneifel W: Comparison of broth microdilution, etest, and agar disk diffusion methods for antimicrobial susceptibility testing of Lactobacillus acidophilus group members. Appl Environ Microbiol 2008, 74:3745-3748.

110. Huys G, D'Haene K, Cnockaert M, Tosi L, Danielsen M, Flórez AB, Mättö J, Axelsson L, Korhonen J, Mayrhofer S, Egervärn M, Giacomini M, Vandamme $P$ : Intra- and Interlaboratory performance of two commercial antimicrobial susceptibility testing methods for bifidobacteria and nonenterococcal lactic acid bacteria. Antimicrob Agents Chemother 2010, 54:2567-2574.

111. Masco L, Huys G, De Brandt E, Temmerman R, Swings J: Culturedependent and culture-independent qualitative analysis of probiotic products claimed to contain bifidobacteria. Int J Food Microbiol 2005, 102:221-230.

112. Tuomola E, Crittenden R, Playne M, Isolauri E, Salminen S: Quality assurance criteria for probiotic bacteria. Am J Clin Nutr 2001, 73(Suppl 2): S393S-S398.

113. Clancy RL, Pang G: Probiotics-industry myth or a practical reality? J Am Coll Nutr 2007, 26:S691S-S694. 
114. Grzeskowiak L, Isolauri E, Salminen S, Gueimonde M: Manufacturing process influences properties of probiotic bacteria. Br J Nutr 2011, 105:887-894.

115. Lo KH: Dietary supplements - are they dangerous?[http://www.buzzle. com/articles/dietary-supplements-dangerous.html], accessed on 20/04/2011.

116. Green A: How do you choose a good probiotic?[http://www.protexin.com/ userfiles/file/

how_do_you_choose_a_good_probiotic_aileen_green_final_lowres.pdf], accessed on 20/04/2011.

117. Patole S, Deshpande G, Abernethy G, Conway P, Keil T, Simmer K: Selecting a probiotic product for preterm neonates: A note of caution. J Pediatr Child Health 2010, 46(S1):64-65.

118. Awad H, Mokhtar H, Imam SS, Gad Gl, Hafez H, Aboushady N: Comparison between killed and living probiotic usage versus placebo for the prevention of necrotizing enterocolitis and sepsis in neonates. Pak J Biol Sci 2010, 13:253-262.

119. Adams CA: The probiotic paradox: live and dead cells are biological response modifiers. Nutr Res Rev 2010, 23:37-46.

120. Kataria J, Li N, Wynn JL, Neu J: Probiotic microbes: do they need to be alive to be beneficial? Nutr Rev 2009, 67:546-550.

121. Olivares M, Díaz-Ropero MP, Martín R, Rodríguez JM, Xaus J: Antimicrobial potential of four Lactobacillus strains isolated from breast milk. J Appl Microbiol 2006, 101:72-79.

122. Boehm G: Oligosacharides in milk. J Nutr 2007, 137(Suppl 3):S847-S849.

123. Su $P$, Henriksson $A$, Mitchell $H$ : Prebiotics enhance survival and prolong the retention period of specific probiotic inocula in an in vivo murine model. J Appl Microbiol 2007, 103:2392-2400.

124. Panigrahi P, Parida S, Pradhan L, Mohapatra SS, Misra PR, Johnson JA, Chaudhry R, Taylor S, Hansen NI, Gewolb IH: Long-term colonization of a Lactobacillus plantarum synbiotic preparation in the neonatal gut. Pediatr Gastroenterol Nutr 2008, 47:45-53.

125. Gueimonde M, Kalliomäki M, Isolauri E, Salminen S: Probiotic intervention in neonates-will permanent colonization ensue? J Pediatr Gastroenterol Nutr 2006, 42:604-606.

126. Canganella F, Paganani S, Ovidi M, Vettraino AM, Bevilacqua L, Massa $S$, Trovatelli LD: A microbiological investigation on probiotic pharmaceutical products used for human health. Microbiol Res 1997, 152:171-179.

127. Drago L, Rodighiero V, Celeste T, Rovetto L, DE Vecchi E: Microbiological evaluation of commercial probiotic products available in the USA in 2009. J Chemother 2011, 22:373-377.

128. Mattia A, Merker R: Regulation of probiotic substances as ingredients in foods: premarket approval or "generally recognized as safe" notification. Clin Infect Dis 2008, 46(Suppl 2):S115-S118, Discussion: S144-151.

129. Hoffman FA: Development of probiotics as biologic drugs. Clin Infect Dis 2008, 46(Suppl 2):S125-S127, Discussion: 144-151.

130. Degnan FH: The US Food and Drug Administration and probiotics: regulatory categorization. Clin Infect Dis 2008, 46(Suppl 2):S133-S136, Discussion: S144-S151.

131. Hibberd PL, Davidson L: Probiotic foods and drugs: impact of US regulatory status on design of clinical trials. Clin Infect Dis 2008, 46(Suppl 2):S137-140, Discussion: S144-151.

132. Henriksson A, Borody T, Clancy R: Probiotics under the regulatory microscope. Expert Opin Drug Saf 2005, 4:1135-1143.

133. Amagase $\mathrm{H}$ : Current marketplace for probiotics: a Japanese perspective. Clin Infect Dis 2008, 46(Suppl 2):S73-S75, Discussion: S144-S151.

134. Tamayo C: Clinical research on probiotics: the interface between science and regulation. Clin Infect Dis 2008, 46(Suppl 2):S101-S103.

135. Gewolb IH, Schwalbe RS, Taciak VL, Harrison TS, Panigrahi P: Stool microflora in ELBW infants. Archives Fetal Neonatal Ed 1999, 80:F167-F173.

136. Saiman L: Strategies for prevention of nosocomial sepsis in the neonatal intensive care unit. Current Opinion in Pediatrics 2006, 18:101-106.

137. Patole $\mathrm{S}$, de Clerk N: Impact of standardised feeding regimen on incidence of neonatal necrotising enterocolitis - a systematic review and meta analysis of observational studies. Arch Dis Child Fetal Neonatal Ed 2005, 90:F147-151.

138. Premji S: Standardised feeding regimens-hope for reducing the risk of necrotising enterocolitis. Arch Dis Child Fetal Neonatal Ed 2005, 90 F192-193.

139. Christensen RD, Gordon PV, Besner GE: Can we cut the incidence of necrotising enterocolitis in half-today? Fetal and Pediatr Pathol 2010 29:185-198.
140. Indrio F, Riezzo G, Raimondi F, Bisceglia M, Cavallo L, Francavilla R: Effect of probiotic and prebiotic on gastrointestinal motility in newborns. J Physiol Pharmacol 2009, 60(Suppl 6):S27-S31.

141. Indrio F, Riezzo G, Raimondi F, Francavilla R, Montagna O, Valenzano ML, Cavallo L, Boehm G: Prebiotics improve gastric motility and gastric electrical activity in preterm newborns. J Pediatr Gastroenterol Nutr 2009, 49:258-261.

142. Indrio F, Riezzo G, Raimondi F, Bisceglia M, Cavallo L, Francavilla R: The effects of probiotics on feeding tolerance, bowel habits, and gastrointestinal motility in preterm newborns. J Pediatr 2008, 152:801-806.

143. Lara-Villoslada F, Olivares M, Sierra S, Rodríguez JM, Boza J, Xaus J: Beneficial effects of probiotic bacteria isolated from breast milk. $\mathrm{Br} J$ Nutr 2007, 98(Suppl 1):S96-S100.

144. Bertino E, Coppa GV, Giuliani F, Coscia A, Gabrielli O, Sabatino G, Sgarrella M, Testa T, Zampini L, Fabris C: Effects of Holder pasteurization on human milk oligosaccharides. Int J Immunopathol Pharmacol 2008, 21:381-385.

145. Hammerman C, Bin-Nun A, Kaplan M: Safety of probiotics: comparison of two popular strains. BMJ 2006, 333:1006-1008.

146. Guidelines for the Evaluation of Probiotics in Food Report of a Joint FAO/WHO Working Group on Drafting Guidelines for the Evaluation of Probiotics in Food London Ontario, Canada April 30 and May 1, 2002. [http://www.who.int/foodsafety/fs_management/en/probiotic guidelines. pdf], Accessed on April 25, 2011.

147. Kataria J, Li N, Wynn JL, Neu J: Probiotic microbes: do they need to be alive to be beneficial? Nutr Rev 2009, 67:546-550.

148. Tao Y, Drabik KA, Waypa TS, Musch MW, Alverdy JC, Schneewind O, Chang EB, Petrof EO: Soluble factors from Lactobacillus GG activate MAPKs and induce cytoprotective heat shock proteins in intestinal epithelial cells. Am J Physiol Cell Physio/ 2006, 290:C1018-C1030.

149. Kelly P, Maguire PB, Bennett M, Fitzgerald DJ, Edwards RJ, Thiede B, Treumann A, Collins JK, O Sullivan GC, Shanahan F, Dunne C: Correlation of probiotic Lactobacillus salivarius growth phase with its cell wallassociated proteome. FEMS Microbiology Letters 2005, 252:153-159.

150. Mogna G, Strozzi GP, Mogna L: Allergen-free probiotics. J Clin Gastroenterol 2008, 42(Suppl 3 Pt 2):S201-S204

151. Ananta $E$ : Impact of environmental factors on viability and stability and high pressure pretreatment on stress tolerance of Lactobacillus rhamnosus GG (ATCC 53103) during spray drying.[http://deposit.ddb.de/ cgibin/dokserv?

idn=976924277\&dok_var=d1\&dok_ext=pdf\&filename=976924277.pdf], accessed on April 20, 2011

152. Danish National Guideline: probiotics for preterm GA 30 weeks [in Danish]. [http://www.rh-vejledninger.dk/C1256FF60 028FE3A/0/ FADF649DDFCAFF2FC12576AB0030868D? OpenDocument\&Highlight_2], Accessed October 20, 2010

153. Kuzma-O'Reilly B, Duenas ML, Greecher C, Kimberlin L, Mujsce D, Miller D, Walker DJ: Evaluation, development, and implementation of potentially better practices in neonatal intensive care nutrition. Pediatrics 2003,111: e461-e470.

154. Schmolzer G, Urlesberger B, Haim M, Kutschera J, Pichler G, Ritschl E, Resch B, Reiterer F, Müller W: Multi-modal approach to prophylaxis of necrotizing enterocolitis: clinical report and review of literature. Pediatr Surg Int 2006, 22:573-580.

\section{Pre-publication history}

The pre-publication history for this paper can be accessed here: http://www.biomedcentral.com/1741-7015/9/92/prepub

doi:10.1186/1741-7015-9-92

Cite this article as: Deshpande et al.: Evidence-based guidelines for use of probiotics in preterm neonates. BMC Medicine 2011 9:92 